\title{
Success Criteria and Preclinical Testing of Multifunctional Hydrogels for Tendon Regeneration
}

\author{
Ryan C. Locke, PhD, ${ }^{1, *}$ Eden M. Ford, BS, ${ }^{2, *}$ Karin G. Silbernagel, PhD, ${ }^{3}$ \\ April M. Kloxin, PhD, ${ }^{2,4}$ and Megan L. Killian, $\mathrm{PhD}^{1,5}$
}

Tendon injuries are difficult to heal, in part, because intrinsic tendon healing, which is dominated by scar tissue formation, does not effectively regenerate the native structure and function of healthy tendon. Further, many current treatment strategies also fall short of producing regenerated tendon with the native properties of healthy tendon. There is increasing interest in the use of cell-instructive strategies to limit the intrinsic fibrotic response following injury and improve the regenerative capacity of tendon in vivo. We have established multifunctional, cell-instructive hydrogels for treating injured tendon that afford tunable control over the biomechanical, biochemical, and structural properties of the cell microenvironment. Specifically, we incorporated integrin-binding domains (RGDS) and assembled multifunctional collagen mimetic peptides that enable cell adhesion and elongation of stem cells within synthetic hydrogels of designed biomechanical properties and evaluated these materials using targeted success criteria developed for testing in mechanically demanding environments such as tendon healing. The in vitro and in situ success criteria were determined based on systematic reviews of the most commonly reported outcome measures of hydrogels for tendon repair and established standards for testing of biomaterials. We then showed, using validation experiments, that multifunctional and synthetic hydrogels meet these criteria. Specifically, these hydrogels have mechanical properties comparable to developing tendon; are noncytotoxic both in two-dimensional bolus exposure (hydrogel components) and three-dimensional encapsulation (full hydrogel); are formed, retained, and visualized within tendon defects over time (2-weeks); and provide mechanical support to tendon defects at the time of in situ gel crosslinking. Ultimately, the in vitro and in situ success criteria evaluated in this study were designed for preclinical research to rigorously test the potential to achieve successful tendon repair before in vivo testing and indicate the promise of multifunctional and synthetic hydrogels for continued translation.

Keywords: collagen mimetic peptides, multifunctional synthetic biomaterials, in situ photopolymerization, tendon injury models, therapeutic strategies, preclinical translation, hydrogels

\section{Impact Statement}

Tendon healing results in a weak scar that forms due to poor cell-mediated repair of the injured tissue. Treatments that tailor the instructions experienced by cells during healing afford opportunities to regenerate the healthy tendon. Engineered cell-instructive cues, including the biomechanical, biochemical, and structural properties of the cell microenvironment, within multifunctional synthetic hydrogels are promising therapeutic strategies for tissue regeneration. In this article, the preclinical efficacy of multifunctional synthetic hydrogels for tendon repair is tested against rigorous in vitro and in situ success criteria. This study indicates the promise for continued preclinical translation of synthetic hydrogels for tissue regeneration.

\footnotetext{
Departments of ${ }^{1}$ Biomedical Engineering, ${ }^{2}$ Chemical and Biomolecular Engineering, ${ }^{3}$ Physical Therapy, and ${ }^{4}$ Materials Science and Engineering, University of Delaware, Newark, Delaware, USA.

${ }^{5}$ Department of Orthopaedic Surgery, University of Michigan Medical School, Ann Arbor, Michigan, USA.

*Shared first authors.
} 


\section{Introduction}

$\mathbf{N}$ EARLY HALF OF THE 26.3 million musculoskeletal injuries and procedures in the United States each year involve tendons. ${ }^{1}$ Although current treatment strategies for injured tendons (e.g., sutures and grafts) increase the acute mechanical function of tendon after injury, reinjury rates remain high as the challenge of tendon regeneration is not solely mechanical in nature. ${ }^{2-7}$ Healthy tendon is not regenerated following injury and often heals via formation of fibrotic and mechanically weak scar tissue. ${ }^{7-9}$ Therefore, new treatment strategies are needed to provide cellular instructions that shift the healing response from fibrotic to regenerative.

Natural and synthetic hydrogels range in material type and functionality and have been used in in vitro and in vivo studies for tendon healing; yet, a broad range of outcome measures have been reported to determine their preclinical safety and success. A standardized list of in vitro and in situ success criteria to meet before in vivo testing would benefit researchers for the rigorous and systematic testing of hydrogels in mechanically demanding environments such as tendon repair.

Guidelines to evaluate biomaterials for tissue repair include those generally defined by the International Organization for Standardization (ISO 10993) ${ }^{10}$ and by the American Society for Testing and Materials (ASTM, e.g., ASTM F2900 and ASTM F2903). In the literature, expected outcomes have been reported related to tissue-engineered constructs for tendon regeneration in vivo. ${ }^{11-16}$ However, success criteria for evaluating hydrogels designed for tendon repair before in vivo application are not clearly defined. A limitation of hydrogels compared to other tendon repair strategies is the ability of the hydrogel to be retained within the injury site long-term and also provide mechanical support while promoting tenogenic remodeling. ${ }^{17,18}$ Integration of related metrics to evaluate material performance before in vivo implantation would facilitate design and translation of hydrogels for tendon repair.

Hydrogels, including collagen- ${ }^{19}$ and extracellular matrix (ECM)-based ${ }^{20}$ gels, are used as carriers to guide and deliver stem cells. However, the clinical efficacy and the role of transplanted cells in tendon repair remains ambiguous. ${ }^{21}$ Promising new synthetic hydrogels may circumvent the need for stem cell delivery if these materials contain deliberately designed cell-instructive cues, such as cell integrin-binding domains, fibrous ECM-mimetic peptides, tunable mechanical properties, and matrix metalloproteinase (MMP)-degradable linker peptides. ${ }^{17,22}$

Engineered hydrogels, such as functionalized poly(ethylene glycol) (PEG) hydrogels, are designed for delivery of targeted cellular instructions via tunable control of mechanical and biochemical environments. ${ }^{23-26}$ Such cell-instructive hydrogels and scaffolds are attractive alternatives to cell-based tendon therapies because these materials do not rely on allogenic cell use and therefore reduce cell-donor site morbidity and immune rejection. ${ }^{27-34}$ Drawbacks of synthetic hydrogels, however, can include cytotoxicity (e.g., by-products of polymerization steps) or limited mechanical support compared to sutures and fibrous scaffolds. ${ }^{15,17,35}$ Thus, developing innovative material designs that integrate structures reminiscent of those found in native tissues may address these drawbacks and improve preclinical translation for tendon repair.
Most prior reports primarily focused on mechanical and biological outcomes to meet during in vivo tendon healing (Supplementary Table S1). ${ }^{1-16}$ We developed in vitro and in situ success criteria via systematic review of the peerreviewed literature of the most common outcome measures performed on hydrogels intended for tendon repair (Supplementary Data; Supplementary Methods: "Systematic Reviews"; Fig. 1 and Supplementary Figs. S1-S4; Supplementary Table S2). We then searched clinical literature of Achilles tendon and rotator cuff repair to identify the most common outcome measures used to define successful clinical repair (Supplementary Methods: "Systematic Reviews"; Fig. 1 and Supplementary Fig. S5; Supplementary Table S3).

Following outcome measure identification, we crossreferenced these lists with ISO and ASTM standards (Fig. 1 and Supplementary Table S4 and Supplementary Lists $\mathrm{S} 1-\mathrm{S} 3$ ). For the final criterion (Table 1), we performed validation experiments using the hydrogel system described above. The success criteria can be tailored toward the mechanobiological needs from tendon to another tissue (x) or hydrogel (y) using the five-step method in Figure 1.

In this work, we developed and tested in vitro and in situ success criteria for hydrogels in mechanically demanding environments specific for use in tendon repair. We performed

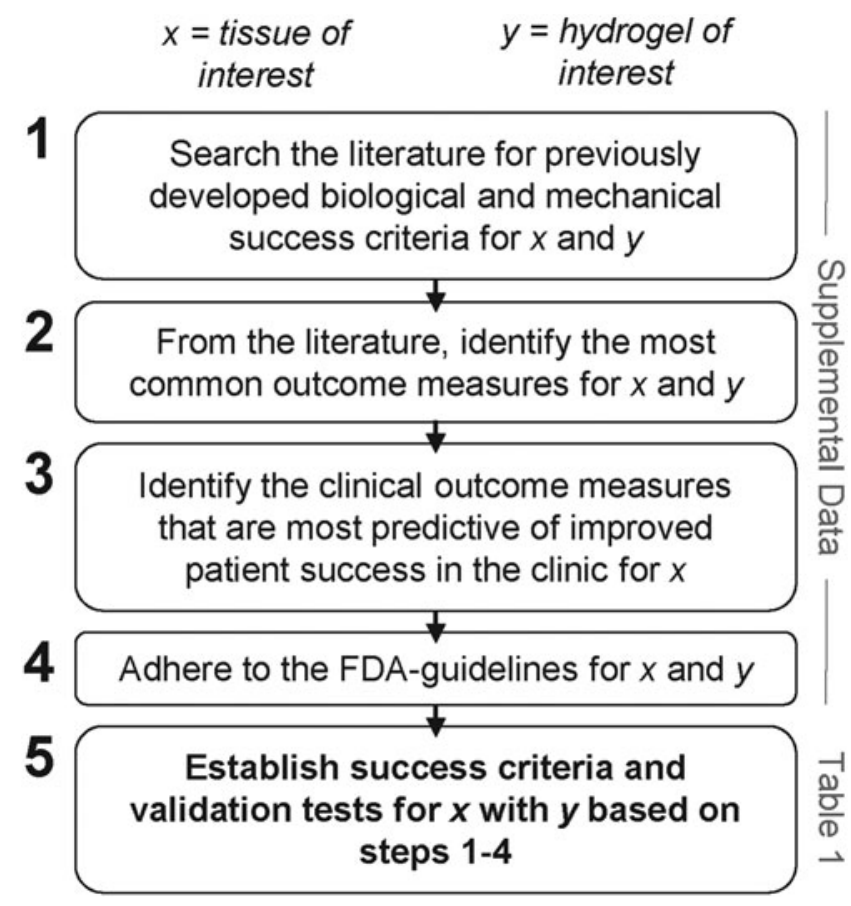

FIG. 1. Study design and method. (1) Literature searches were performed for prior success criteria for tendon repair. Systematic reviews were performed to identify the most common outcome measures for (2) preclinical use of hydrogels for tendon repair and (3) clinical tendon repair. (4) Food and Drug Administration guidelines, specifically the International Organization for Standardization 10993 and American Society for Testing and Materials F2900 and F2903 standards, were cross-referenced. (5) Success criteria and validation tests were established based on the identified gaps in the literature and the findings from (1) to (4). Table 1 outlines the success criteria that we developed and tested in this study for tendon repair using hydrogels. See the Supplementary Data for outcomes from steps (1) to (4). 
Table 1. IN Vitro and IN Situ Success Criteria to Meet for the Regeneration of Injured Tendons with IN Situ Formed, Cell-Instructive Hydrogels

\begin{tabular}{|c|c|c|c|}
\hline & Success criteria & Tests $^{\mathrm{a}}$ & Description of this study \\
\hline $\begin{array}{l}\text { Material } \\
\text { properties }\end{array}$ & $\begin{array}{l}\text { In situ formed with tunable } \\
\text { and physiologically } \\
\text { relevant modulus }\end{array}$ & $\begin{array}{l}\text { Hydrogel mechanical } \\
\text { testing }^{\mathrm{a}}\end{array}$ & $\begin{array}{l}\text { Material properties of developing } \\
\text { tendon compared to gel (Fig. 2) }\end{array}$ \\
\hline $\begin{array}{l}\text { Degradation } \\
\text { profile }\end{array}$ & $\begin{array}{l}\text { Controlled material } \\
\text { degradation profile }\end{array}$ & Enzyme incubations $^{\mathrm{a}}$ & $\begin{array}{l}\text { Prior data validates that our materials } \\
\text { allow controlled degradation }\end{array}$ \\
\hline \multirow[t]{4}{*}{$\begin{array}{l}\text { In vitro } \\
\text { compatibility }\end{array}$} & \multirow{4}{*}{$\begin{array}{l}\text { Maintain viability of both } \\
\text { primary human and animal } \\
\text { cells, while allowing } \\
\text { molecular analyses }\end{array}$} & $\begin{array}{l}\text { Individual chemical } \\
\text { cytotoxicity }\end{array}$ & $\begin{array}{l}\text { Culture cells with each hydrogel } \\
\text { component to the media, and test } \\
\text { viability (Fig. 3A) }\end{array}$ \\
\hline & & Bulk cytotoxicity & $\begin{array}{l}\text { Culture cells within 3D hydrogels } \\
\text { and test viability (Fig. 3B) }\end{array}$ \\
\hline & & $\begin{array}{l}\text { Morphology and } \\
\text { migration }^{\mathrm{a}}\end{array}$ & $\begin{array}{l}\text { Culture cells within 3D hydrogels and } \\
\text { perform imaging within the gel }\end{array}$ \\
\hline & & Molecular biology & $\begin{array}{l}\text { and IHC or RNA isolation (Fig. 3B } \\
\text { and Supplementary Fig. S11) }\end{array}$ \\
\hline Material-tissue & Visualize the interface or & Multiscale imaging $^{a}$ & Macroscale images of the hydrogel \\
\hline interface & $\begin{array}{l}\text { direct bond of the material } \\
\text { to the tissue defect }\end{array}$ & Histology & $\begin{array}{l}\text { formed with a rat Achilles tendon } \\
\text { defect (Fig. 4) }\end{array}$ \\
\hline In vivo imaging & $\begin{array}{l}\text { Localize the material when } \\
\text { applied in vivo }\end{array}$ & IVIS $^{\mathrm{TM}}$ tracking & $\begin{array}{l}\text { IVIS }{ }^{\mathrm{TM}} \text { image hydrogel with varying } \\
\text { concentrations of AF647 (Fig. 5) }\end{array}$ \\
\hline $\begin{array}{l}\text { Long-term } \\
\text { retention }\end{array}$ & $\begin{array}{l}\text { In situ formed and retained } \\
\text { within tissue defects long- } \\
\text { term (weeks) }\end{array}$ & $\begin{array}{l}\text { Physiologic incubations } \\
\text { Fatigue testing }\end{array}$ & $\begin{array}{l}\text { Create defect within rat Achilles } \\
\text { tendon, form the hydrogel in the } \\
\text { defect, and incubate the tendon- } \\
\text { hydrogel construct under } \\
\text { physiological conditions (Fig. 6) }\end{array}$ \\
\hline $\begin{array}{l}\text { Mechanical } \\
\text { support }\end{array}$ & $\begin{array}{l}\text { Provide mechanical support } \\
\text { to tissue defects at the time } \\
\text { of injection }\end{array}$ & Load-to-failure testing ${ }^{\mathrm{b}}$ & $\begin{array}{l}\text { Create defect within rat infraspinatus } \\
\text { tendon-bone attachment, form the } \\
\text { hydrogel in the defect, and load-to- } \\
\text { failure (Fig. } 7 \text { ) }\end{array}$ \\
\hline
\end{tabular}

${ }^{\text {a }}$ This list does not include all possible tests, instead it includes the tests that were most commonly performed to validate the use of hydrogels for tendon repair. If there is a specific goal of the repair strategy — for example, to induce cell differentiation - then this list can be adapted to include differentiation markers (RNA/IHC) or cell morphology assays. Rheology is one of the most common mechanical tests for hydrogels.

${ }^{\mathrm{b}}$ At a minimum, hydrogels should increase the fatigue life and ultimate load compared to empty defect controls. Note: Enzyme incubations, cell migration, multiscale imaging (e.g., nano- to macroscale), and fatigue testing were not performed in this study, however, they are important for hydrogel success in tendon repair in vivo and are avenues for future studies.

3D, three-dimensional; IHC, immunohistochemical staining.

validation experiments both in vitro and in situ using preclinical models of tendon injury. In this study, photopolymerized PEG-peptide thiol-ene hydrogels were used (i) with well-defined homogeneous nanostructure ${ }^{25,36,37}$ and (ii) with fibrillar and collagen mimetic nanostructure. ${ }^{23}$ Through testing of synthetic hydrogels against the developed success criteria in the context of tendon repair, we established that multifunctional, cell-instructive synthetic hydrogels hold promise for continued translation for tendon repair.

\section{Method}

\section{Multifunctional collagen mimetic peptide hydrogel}

Hydrogels were designed to be locally cell-degradable, accounting for the need for cell migration and cell-mediated ECM turnover in the context of in vitro and in vivo applications. Specifically, we incorporated into synthetic PEGpeptide hydrogels a MMP-degradable linker (degradable linker peptide), a variant of that found in collagen type-I known to degrade in response to a variety of MMPs, including MMP-1 and MMP-2, which are upregulated during tendon repair. ${ }^{38,39}$ As tendon ECM is primarily fibrous collagen, ${ }^{39,40}$ the incorporation of collagen-like structure may improve tendon repair in vivo. We have therefore in- corporated an assembled, multifunctional collagen mimetic peptide (mfCMP) into this hydrogel system to provide fibrous structure. $^{23}$

Here, to keep degradable content constant with and without mfCMP, a scrambled linker with reduced MMP-specific degradability (scrambled linker peptide) also was incorporated into the network and replaced with the mfCMP (a nondegradable peptide) when desired for increased structural content. In addition, pendant RGDS (an integrin-binding peptide) and a fluorophore were incorporated into the hydrogel network to promote cell adhesion and enable imaging within tissues. The design of this material allows for independent control over modulus, structure, biochemical content, and degradability, which can individually be tuned for mimicking aspects of developing tendon, and enables in situ formation within tendon injuries. All animal studies were performed following according to a IACUC-approved protocol (AUP1296) at the University of Delaware.

\section{Experiment}

\section{Experimental design}

Peptide and mfCMP synthesis. Four peptides in total were synthesized on an automated peptide synthesizer with 
microwave capabilities (Liberty Blue; CEM Corporation, Matthews, NC), using solid phase peptide synthesis techniques according to a previously described protocol. ${ }^{23}$ The two linker peptide variants used in this study included a degradable linker peptide [KK(alloc)GGPQG $\downarrow$ IWGQG$\mathrm{K}($ alloc) $\mathrm{K}]$ and a scrambled linker peptide [KK(alloc)GIQ PGGWGQGK(alloc)K]. Here, K(alloc) is an allyloxycarbonyl-protected lysine residue that presents a reactive handle for light-initiated thiol-ene click chemistry. In addition, a mfCMP $\left[(\mathrm{PKG})_{4} \mathrm{PK}(\right.$ alloc $) \mathrm{G}(\mathrm{POG})_{6}(\mathrm{DOG})_{4}$, where $\mathrm{O}$ is a hydroxyproline residue] and an integrin-binding peptide [RGDS, K(alloc)GWGRGDS] were synthesized to impart fibrillar structure and cell adhesion, respectively (Supplementary Methods: "Peptide synthesis" and "mfCMP synthesis").

All peptides were purified by high performance liquid chromatography (HPLC, XBridge C18 OBD $5 \mu \mathrm{m}$ column, linear gradients described in "Supplementary Methods: "Peptide synthesis",." Collected fractions were frozen, lyophilized, and products were confirmed via electrospray ionization (ESI+) mass spectrometry (Xevo G2-S QTof; Waters Corporation, Milford, MA) (Supplementary Fig. S6). Stock solutions of all peptides were prepared in Dulbecco's phosphate-buffered saline (PBS). mfCMP concentrations were determined by weight, and ultraviolet-visible (UV-VIS) spectrometry (NanoDrop ${ }^{\mathrm{TM}}$ 2000c Spectrophotometer; Thermo Fisher Scientific, Waltham, MA) was used to confirm stock solution concentrations of all other peptides via converting tryptophan absorbance at $280 \mathrm{~nm}$ to peptide concentration (Beer's law, $\varepsilon_{280, \text { Tryptophan }}=5690 \mathrm{M}^{-1} \mathrm{~cm}^{-1}$ ). ${ }^{23}$

Hydrogel design, photopolymerization, and rheometry. Four-arm PEG with hydroxyl end groups (PEG-4OH; JenKem, $M_{n} \sim 20 \mathrm{kDa}$ ) was modified with thiol end groups as previously described, ${ }^{23,41}$ producing hydrogel precursor PEG-4SH (Supplementary Methods: "PEG-4SH modification"; Supplementary Fig. S7B). PEG-4SH was diluted into PBS (25 mM thiol functional groups) and Alexa Fluor ${ }^{\mathrm{TM}} 647$ $\mathrm{C}_{2}$ Maleimide (Thermo Fisher Scientific) was added targeting $0.5 \%$ thiol conjugation with the fluorophore (Fig. 5A; $80 \mu \mathrm{M}$ AF647:16 mM thiols in the final hydrogel precursor solution, 1-h reaction, modified from manufacturer's protocol). All hydrogels were fluorescently labeled with Alexa Fluor $^{\mathrm{TM}} 647$ (AF647), where $80 \mu \mathrm{M}$ AF647 was used for in situ imaging in tendon, unless otherwise stated.

Hydrogel precursor solutions were prepared before photopolymerization and contained $8 \mathrm{wt} \%$ PEG-4SH, degradable linker peptide, scrambled linker peptide $(1.25 \mathrm{mM}$, $2.5 \mathrm{mM}$ alloc; $0 \mathrm{mM}$ mfCMP condition) or mfCMP (2.5 mM, $2.5 \mathrm{mM}$ alloc; $2.5 \mathrm{mM}$ mfCMP condition), and RGDS such that thiol and alloc functional groups were stoichiometrically balanced (16 mM thiol:16 mM alloc) unless otherwise stated. The RGDS peptide was incorporated at $2 \mathrm{mM}$ ( $2 \mathrm{mM}$ alloc), and degradable content was kept constant with $5.75 \mathrm{mM}$ degradable linker peptide $(11.5 \mathrm{mM}$ alloc) incorporation. All solutions included $2.2 \mathrm{mM}$ lithium phenyl-2,4,6-trimethylbenzoylphosphinate (LAP) photoinitiator synthesized by previously published protocols (Supplementary Methods: "LAP synthesis"; Supplementary Fig. S7A). ${ }^{42}$

Hydrogel precursor solutions $(20 \mu \mathrm{L})$ were transferred to molds (sterile $1 \mathrm{~mL}$ flat-plunger syringes with tips removed; Thermo Fisher Scientific) and irradiated with cytocompa- tible doses of collimated long wavelength UV light for 4 min $\left(365 \mathrm{~nm}, 10 \mathrm{~mW} / \mathrm{cm}^{2}\right.$; Exfo Omnicure Series 2000 light source, $365 \mathrm{~nm}$ bandpass filter; Excelitas Technologies Corp., Waltham, MA). ${ }^{23}$

Hydrogels ( 8 wt\%; $80 \mu \mathrm{M}$ AF647; 0 and $2.5 \mathrm{mM}$ mfCMP conditions) were formed in situ on a AR-G2 rheometer with a quartz plate UV-curing light accessory (TA Instruments, New Castle, DE). A liquid-filled light guide was used to attach the UV curing light accessory to a UV-VIS light source with bandpass filter (Exfo Omnicure Series 2000 light source, $365 \mathrm{~nm}$ bandpass filter). Hydrogel precursor solutions $(10 \mu \mathrm{L})$ were pipetted onto the quartz plate, and an $8 \mathrm{~mm}$ flat plate top was lowered to a $160 \mu \mathrm{m}$ gap height.

Storage modulus $\left(\mathrm{G}^{\prime}\right)$ measurements were collected at room temperature with $1 \%$ strain and $2 \mathrm{rad} / \mathrm{s}$ frequency (within the linear viscoelastic regime). Measurements were taken for $60 \mathrm{~s}$ before irradiation followed by $4 \mathrm{~min}$ of irradiation $\left(365 \mathrm{~nm}, 10 \mathrm{~mW} / \mathrm{cm}^{2}\right)$ to monitor complete hydrogel formation, at which point the final modulus measurements were determined. $\mathrm{G}^{\prime}$ was converted to elastic modulus (Young's modulus, E) using rubber elasticity theory ${ }^{43}$ assuming a Poisson's ratio of 0.5 for these elastic, incompressible hydrogels and compared to the elastic modulus of developing chick tendon ${ }^{44}$ (Supplementary Methods: "Modulus conversion"). Note that 2 min of irradiation was determined to be sufficient for complete gelation and was used in individual chemical cytotoxicity and mechanical testing experiments.

Cell culture experiments. One adult female Long Evans rat was euthanized via carbon dioxide asphyxiation. Immediately, long bones were dissected and rat bone marrow mesenchymal stem/stromal cells (rBMSCs) isolated using a modified version of a published protocol (Supplementary Methods: "rBMSC culture") ). ${ }^{45}$ rBMSCs were cultured on a $100 \mathrm{~mm}^{2}$ Petri dish in growth media (Dulbecco's modified eagle medium [DMEM], and $1 \%$ penicillin, streptomycin, amphotericin, Genesee Scientific; and $10 \%$ fetal bovine serum [FBS]; Atlanta Biologics) at $37^{\circ} \mathrm{C}$ and $5 \% \mathrm{CO}_{2}$. Media was replaced every 2 days. rBMSCs were passaged at 1 week (Passage 1, P1) and cultured until $85 \%$ confluency before cytotoxicity studies described below (performed at P2).

Human mesenchymal stem/stromal cells (hMSCs; Lonza, Basel, Switzerland) derived from bone marrow were expanded on tissue culture-treated polystyrene flasks $\left(182 \mathrm{~cm}^{2}\right.$; CELLTREAT, Pepperell, MA) at $37^{\circ} \mathrm{C}$ and $5 \% \mathrm{CO}_{2}$ using standard sterile technique. hMSCs were thawed and cultured in growth media (low-glucose DMEM with penicillin, streptomycin, Fungizone, and $10 \% \mathrm{v} / \mathrm{v}$ FBS, all from Thermo Fisher Scientific; with $1 \mathrm{ng} / \mathrm{mL}$ basic fibroblast growth factor [bFGF]; PeproTech, Rocky Hill, NJ). Media was replaced every 3-4 days, and hMSCs were passaged once cells reached $85 \%$ confluency. All hMSC experiments were conducted with cells at P6-7.

For experiments, hMSCs and rBMSCs were plated at 15,000 cells $/ \mathrm{cm}^{2}$ in 96 -well plates and cultured overnight before treatment. Cells were exposed to one of five treatments: (i) negative control (2-min PBS incubation), (ii) long wavelength UV light (2-min in PBS; $365 \mathrm{~nm} ; 10 \mathrm{~mW} / \mathrm{cm}^{2}$ ), (iii) blue light ( $2 \mathrm{~min}$ in PBS; $400-500 \mathrm{~nm}$ bandpass filter; $\left.10 \mathrm{~mW} / \mathrm{cm}^{2}\right)$, (iv) radical exposure ( $2 \mathrm{~min}$ in PBS with $0.2 \mathrm{mM}$ LAP; $365 \mathrm{~nm} ; 10 \mathrm{~mW} / \mathrm{cm}^{2}$ ), and (v) all hydrogel 
components ( $2 \mathrm{~min}$ in PBS with $0.2 \mathrm{mM}$ LAP, $0.5 \mathrm{mM}$ degradable linker peptide and $1 \mathrm{mM} \mathrm{L-Cysteine,} 365 \mathrm{~nm}$, $10 \mathrm{~mW} / \mathrm{cm}^{2}$ ) (Exfo Omnicure Series 2000 light source with liquid light guide with collimating lens and respective bandpass filter; Excelitas Technologies Corp.). L-cysteine was used in place of PEG-4SH to mimic hydrogel formation conditions without gelation, allowing cell exposure to the photoinitiated thiol-ene reaction.

After treatment, cells were allowed to recover overnight in growth media. alamarBlue ${ }^{\mathrm{TM}}$ (Thermo Fisher Scientific) was used to measure metabolic activity (Supplementary Methods: "alamarBlue $\left.{ }^{\mathrm{TM}, "}\right)$ and the fluorescence was measured on a plate reader (ex/em: 570/585; Synergy 2 plate reader; BioTek, Winooski, VT).

Three-dimensional cell encapsulation, viability, and collagen deposition. hMSCs were encapsulated within hydrogels that were not fluorescently labeled $(6 \mathrm{wt} \% ; 0 \mu \mathrm{M}$ AF647; 0 and $2.5 \mathrm{mM}$ mfCMP conditions; Supplementary Methods: "3D cell encapsulation"). ${ }^{23}$ Two hydrogel conditions were prepared: without mfCMP (2 mM RGDS, $5 \mathrm{mM}$ degradable linker peptide) and with mfCMP (2 mM RGDS, $3.75 \mathrm{mM}$ degradable linker peptide, $2.5 \mathrm{mM} \mathrm{mfCMP}$ ). hMSCs were suspended in the hydrogel precursor solution at $3.75 \times 10^{6}$ cells $/ \mathrm{mL}$, and $20 \mu \mathrm{L}$ cell-encapsulated hydrogels were formed in syringe molds following procedures described above, under sterile conditions. Hydrogels were transferred to a nontreated 48-well plate with bFGF-free media $(500 \mu \mathrm{L}$; Supplementary Methods: "3D cell encapsulation") and incubated at $37^{\circ} \mathrm{C}$ and $5 \% \mathrm{CO}_{2}$ using standard sterile technique. Media was replaced every 2 days.

Encapsulated hMSC viability was assessed 3-days after encapsulation using a commercially available kit (Live/Dead ${ }^{\mathrm{TM}}$ mammalian cell viability kit; Thermo Fisher Scientific).

Z-stacks $(200 \mu \mathrm{m})$ were acquired using a confocal microscope (Zeiss LSM 800; Zeiss, Oberkochen, Germany). Orthogonal projections were used to count the number of live and dead cells in ImageJ. ${ }^{46}$

After 16-days of culture, hydrogels were fixed in $4 \%$ methanol-free paraformaldehyde (PFA; Thermo Fisher Scientific) and washed in bovine serum albumin-containing PBS (BSA; MilliporeSigma, Burlington, MA). Hydrogels were incubated in a BSA blocking solution then washed in $0.2 \% \mathrm{v} / \mathrm{v}$ TWEEN ${ }^{\circledR} 20$ (MilliporeSigma). Triton ${ }^{\mathrm{TM}} \mathrm{X}-100$ (Thermo Fisher Scientific) was used to permeabilize cells for $30 \mathrm{~min}$. Hydrogels were then incubated sequentially with rabbit-anti-human collagen type-I antibody (ab34710; Abcam, Cambridge, United Kingdom), fluorescently labeled goat-anti-rabbit secondary antibody (Thermo Fisher Scientific), and Hoechst (Thermo Fisher Scientific). Control experiments demonstrate that this antibody does not strongly interact with these mfCMPs, where diffuse background staining is observed for mfCMP hydrogels without cells (Supplementary Fig. S8), and thus the strong, specific staining of large fibrils in the pericellular space surrounding cells indicates the presence of cell-secreted collagen type-I.

Z-stacks $(200 \mu \mathrm{m})$ were acquired via confocal microscope and orthogonal projections were produced for analysis. Toward studying behavior of cells in response to these materials, we also developed a protocol for extracting RNA from hydrogels with low numbers of cells (e.g., hMSCs,
Supplementary Methods: "RNA isolation from synthetic hydrogels"; Supplementary Fig. S9).

Ex vivo studies. Achilles tendons of adult, female Long Evans rats that were euthanized and fresh frozen were used in this study (fresh frozen, $N=8$ ). A $1 \mathrm{~mm}$ biopsy punch was used to make a circular defect in the center third of the Achilles tendon midsubstance $\sim 3 \mathrm{~mm}$ above the Achillescalcaneus attachment ( $n=6$, defect group). For complete laceration, a \#11 scalpel blade was used $\sim 3 \mathrm{~mm}$ above the Achilles-calcaneus attachment to make a complete laceration ( $n=6$, laceration group). Two, nondamaged tendons were used as uninjured controls $(n=2)$. Note that $N$ denotes the number of rats and $n$ denotes the number of tendons.

Following laceration, the two tendon stumps were approximated end-to-end before hydrogel formation (Supplementary Video S1). Hydrogel precursor solutions (8 wt\%; $80 \mu \mathrm{M}$ AF647; 0 and $2.5 \mathrm{mM}$ mfCMP compositions) were pipetted into the tendon defects and photopolymerized with a collimated lamp following procedures described above (365 nm, $10 \mathrm{~mW} / \mathrm{cm}^{2}$, Supplementary Methods: "Formation in Achilles defects"). The interface between the tendon and hydrogel was imaged with a digital camera (Supplementary Video S1; TG-860; Olympus). Tendons were stored in conical tubes with PBS and penicillin, streptomycin, and amphotericin.

To probe what fluorophore concentration was sufficient for in situ imaging, AF647-labeled hydrogels $(20 \mu \mathrm{L})$ were formed with $10,50,80$, or $100 \mu \mathrm{M}$ AF647; immediately swelled in PBS for $2 \mathrm{~h}$; and then imaged. Hydrogels were imaged using an IVIS $^{\text {TM }}$ (Perkin Elmer) with or without rat skin between the hydrogel and camera.

Tendon-hydrogel constructs $(n=12$ tendons) were agitated on an oscillating rocker $\left(1 \mathrm{~Hz}, 22^{\circ} \mathrm{C}\right.$ unless otherwise noted) for 2 weeks to assess long-term retention of hydrogels. Tendon-hydrogel constructs were imaged using the IVIS $^{\mathrm{TM}}$ in vivo imaging system. Images were taken using the IVIS $^{\text {TM }}$ after 2,4 , and $6 \mathrm{~h}$ and $1,3,5,7$, and 14 days of oscillation. The radiant efficacy and integrity (defined as present or not present; broken or not broken) were recorded.

Mechanical testing of hydrogels within partial-thickness rotator cuff injury model. The rotator cuff tendons of freshfrozen adult female Long Evans rats were used in this study $(N=6$ rats with defects, $N=1$ intact healthy attachment control). Partial-thickness defects were made bilaterally at the center of the infraspinatus tendon attachment using a $300 \mu \mathrm{m}$ biopsy punch as previously published $(n=12)^{47,48}$ and humeri were potted in poly-methyl methacrylate (OrthoJet BCS; Lang Dental, Wheeling, IL). ${ }^{48}$

Defects received either hydrogel $(n=6)$ or saline (empty control group, $n=6)$ for paired comparisons. Hydrogels without mfCMP $(10 \mu \mathrm{L} ; 10 \mathrm{wt} \% ; 2 \mathrm{mM}$ RGDS; $9 \mathrm{mM}$ degradable linker peptide) were formed by photopolymerization ( $2 \mathrm{~min}, 365 \mathrm{~nm}, 10 \mathrm{~mW} / \mathrm{cm}^{2}$ ). After hydrogel formation, all samples from both defect groups $(n=12)$ and healthy attachments $(n=2)$ were incubated in PBS at $37^{\circ} \mathrm{C}$ for $1 \mathrm{~h}$ to simulate physiological conditions and induce hydrogel swelling. Samples were subjected to uniaxial tensile tests as follows: $0.2 \mathrm{~N}$ tare load applied with five preconditioning cycles $( \pm 0.05 \mathrm{~mm})$ and load to failure at $0.01 \mathrm{~mm} / \mathrm{s}$. The cross-sectional area (assumed circular) and gauge length 
were measured at the start of each test and mechanical properties were calculated using a custom MATLAB script. ${ }^{48}$

Statistics. Storage moduli and three-dimensional (3D) culture viability were compared between $0 \mathrm{mM}$ mfCMP and $2.5 \mathrm{mM}$ mfCMP hydrogels using unpaired Student's $t$-tests. Metabolic activity of all the treated groups was compared using one-way analysis of variance (ANOVA) with Tukey's post hoc test. Radiant efficiency was compared between the four individual groups using repeated measures (time) two-way ANOVAs with Tukey's post hoc test. Because no differences were observed between groups, all groups were then combined and analyzed by repeated measures (time) one-way ANOVA with Tukey's post hoc test, and the grouped data were fit using a one phase decay. Metabolic activity (background: 0, control average: 100) and radiant efficiency (detectable limit: 0, 2-h average: 100) were linearly normalized for graphical representation. Mechanical properties of the injured infraspinatus attachment with and without hydrogels were compared using paired Student's $t$-tests.

\section{Experimental Results}

\section{Success criteria}

We developed a list of in vitro and in situ success criteria for evaluation of hydrogels in mechanically demanding environments before their use within in vivo applications (Fig. 1; Table 1) and tested each of these criteria with synthetic, multifunctional hydrogels. We identified 12 outcome measures that were most frequently reported in the literature, and, of these, all were also reported in standard guides (Supplementary Tables S1-S4). Preclinical outcomes concentrated on histological, biomechanical, and biochemical assays, while clinical outcomes focused on repair integrity through postoperative imaging, joint function, and surgical complications and were similar between tendons (Supplementary Tables S2 and S3).

Hydrogel material properties. Crosslinked hydrogels with and without assembled mfCMP (Fig. 2A) reached full gelation after $2 \mathrm{~min}$ of irradiation with low-intensity and long wavelength UV light $(\leq 1 \%$ change in modulus)
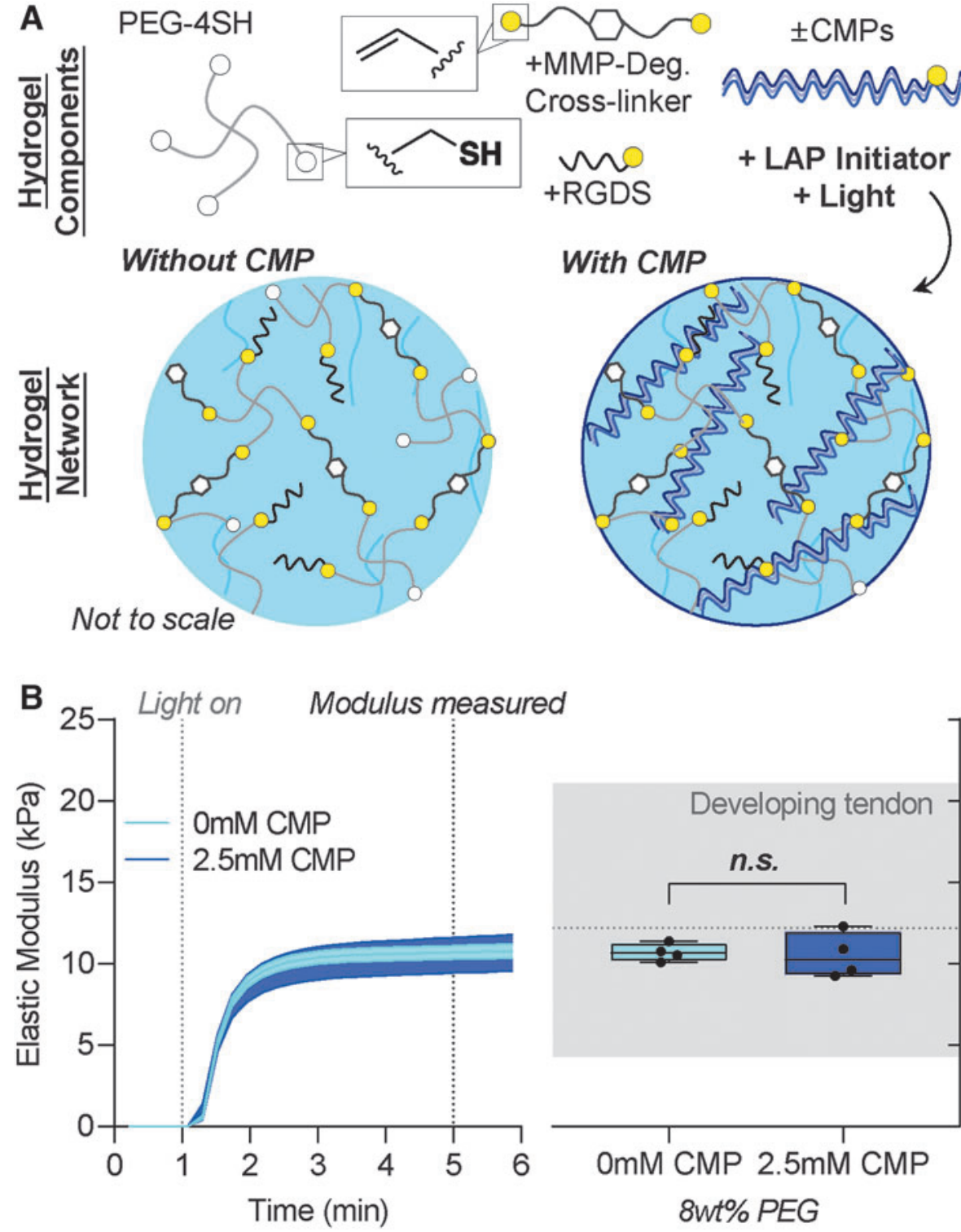

FIG. 2. Hydrogel design, photopolymerization, and mechanical properties. (A) Hydrogel precursors, including PEG-4SH, a MMPdegradable linker peptide, RGDS cell-adhesive peptide, and assembled fibrillar mfCMPs (noted as CMPs within figure), were combined with a photoinitiator (LAP) and then irradiated by long wavelength ultraviolet light $\left(10 \mathrm{~W} / \mathrm{cm}^{2}\right.$ at $365 \mathrm{~nm}$ ) to form hydrogel networks. (B) Storage modulus was monitored during in situ formation and converted to elastic modulus using rubber elasticity theory for ease of comparison to the mechanical properties of tissues (left, mean \pm standard deviation). Elastic moduli of hydrogels formed in situ with and without mfCMP were measured after 4 min of irradiation and are similar to the elastic modulus of developing chick tendon (right, gray bar; $4.3-21.1 \mathrm{kPa}$, dotted line: $12.2 \mathrm{kPa}$ at embryonic day HH41). Data are presented as median $\pm 95 \%$ confidence interval. $^{44}$ LAP, lithium phenyl-2,4,6trimethylbenzoylphosphinate; PEG, poly(ethylene glycol); mfCMP, multifunctional collagen mimetic peptide; MMP, matrix metalloproteinase. Color images are available online. 
(Fig. 2B). We observed no significant difference in in situ elastic modulus between hydrogels with mfCMP (10.5 \pm $0.7 \mathrm{kPa})$ compared to those without $\mathrm{mfCMP}(10.7 \pm 0.3 \mathrm{kPa})$, and both were in the range of published values for developing chick tendon ${ }^{44}$ (Fig. 2B). After equilibrium swelling, owing to water uptake, the elastic modulus of the hydrogels decreased to $4.4 \pm 0.3 \mathrm{kPa}$ (Supplementary Methods: "Equilibrium swollen gel modulus measurements"; Supplementary Fig. S10), which is still within the range of developing chick tendon. ${ }^{44}$

\section{Cell compatibility}

In two-dimensional culture (Fig. 3A), doses of light required for hydrogel formation (either blue or long wavelength UV light) with or without all individual components to create the reaction used for hydrogel formation did not influence cell metabolic activity (Fig. 3A). However, without monomers to scavenge radicals, irradiation in presence of photoinitiator alone led to decreased metabolic activity and differences in cell morphology and number (Fig. 3A). In 3D cell encapsulation (Fig. 3B), the viability of hMSCs was $\sim 80 \%$ both with and without mfCMP after 3 days (Fig. 3B and Supplementary Fig. S11), further supporting cytocompatibility of hydrogel formation.

After long-term encapsulation, collagen type-I localization was observed in the pericellular matrix and hMSCs were more elongated in the presence of mfCMP (Fig. 3B). Early stages of hMSC elongation in the presence of mfCMP were observed after 3 days of encapsulation (Supplementary Fig. S11). Further, RNA yield was acceptable from individual hydrogels at 3 and 19 days following hMSC 3D culture (Supplementary Fig. S9).

Tissue-material interface. Hydrogels were formed at the defect site of full-thickness defects and complete lacerations through rat Achilles tendons (Fig. 4). The hydrogel
FIG. 3. Hydrogel conditions are compatible with human and rat cells in 2D and 3D culture. (A) 2D cell culture schematic of the hydrogel and free radical culture conditions. Normalized metabolic activity of rat and human MSCs in 2D culture after exposure to different aspects of hydrogel formation, and example monolayer images of rat MSCs stained for F-actin (red) and nuclei (Hoechst, blue). (B) 3D cell encapsulation schematic, hMSC viability after 3 days of 3D encapsulation, and human collagen type-I immunostaining of hMSCs within hydrogels after 10 days of 3D encapsulation (6 wt\% gel). Data are presented as mean \pm standard deviation. Black bars: significant difference between groups $(p<0.05)$. 2D, two-dimensional; 3D, three-dimensional; MSC, human mesenchymal stem/stromal cell. Color images are available online.

\section{A 2D Culture: Individual Chemical Cytoxicity}
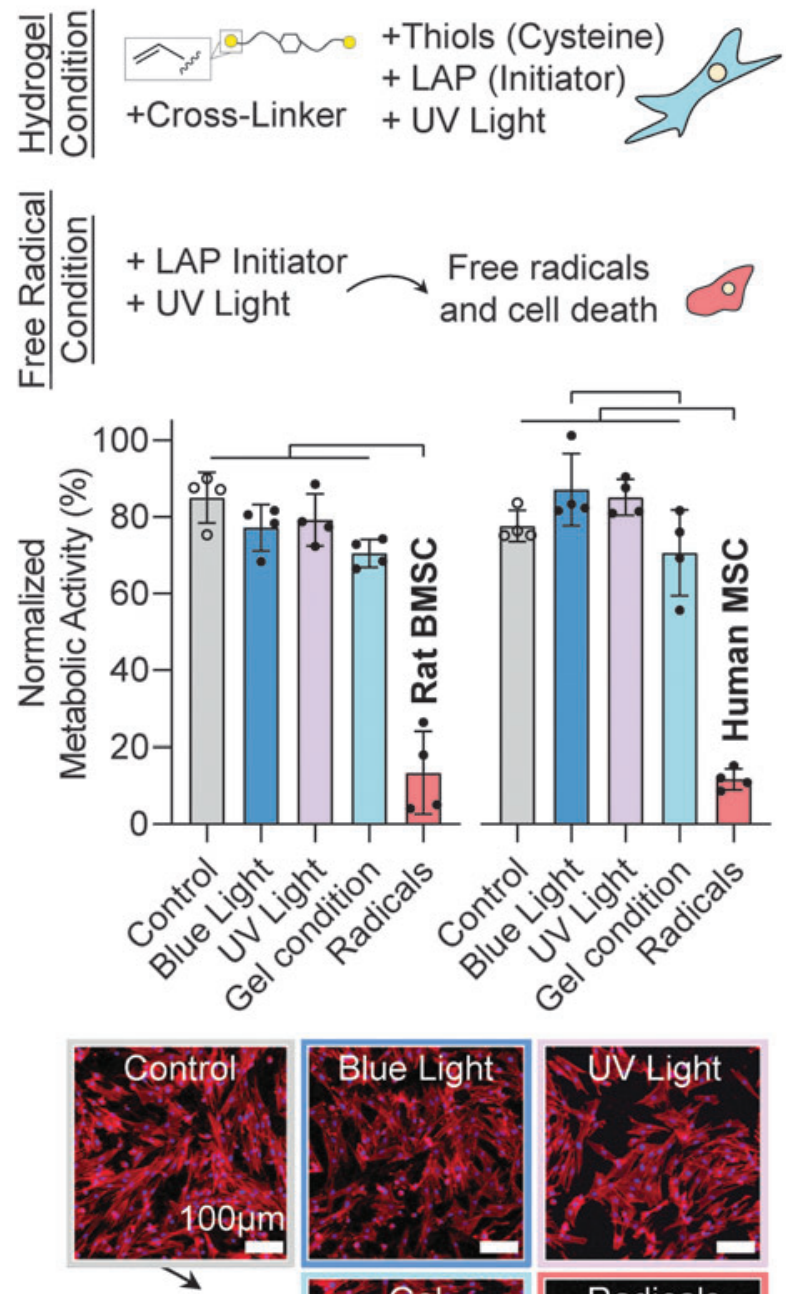

Rat BMSC

stained with

F-actin

Hoechst
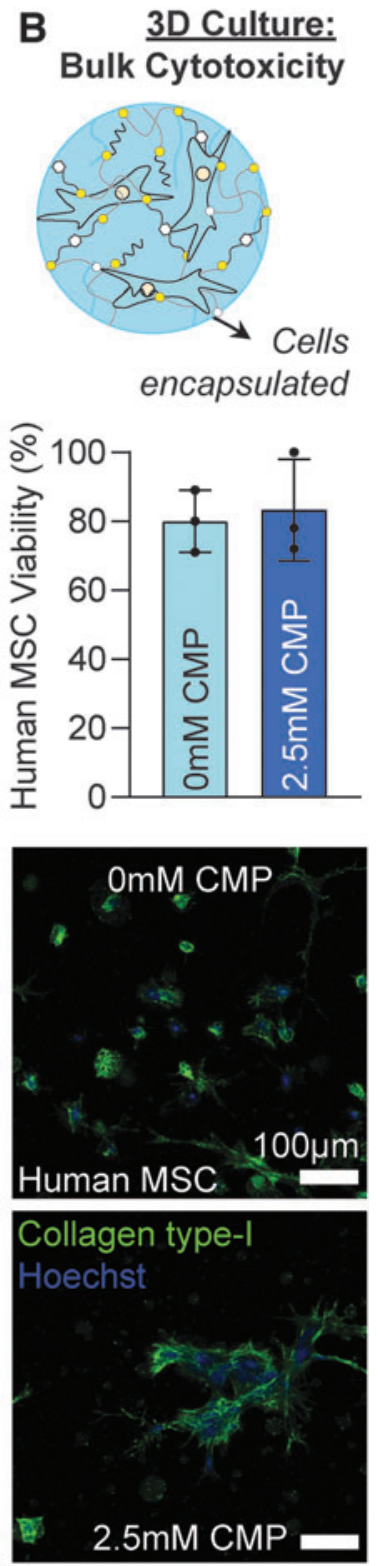


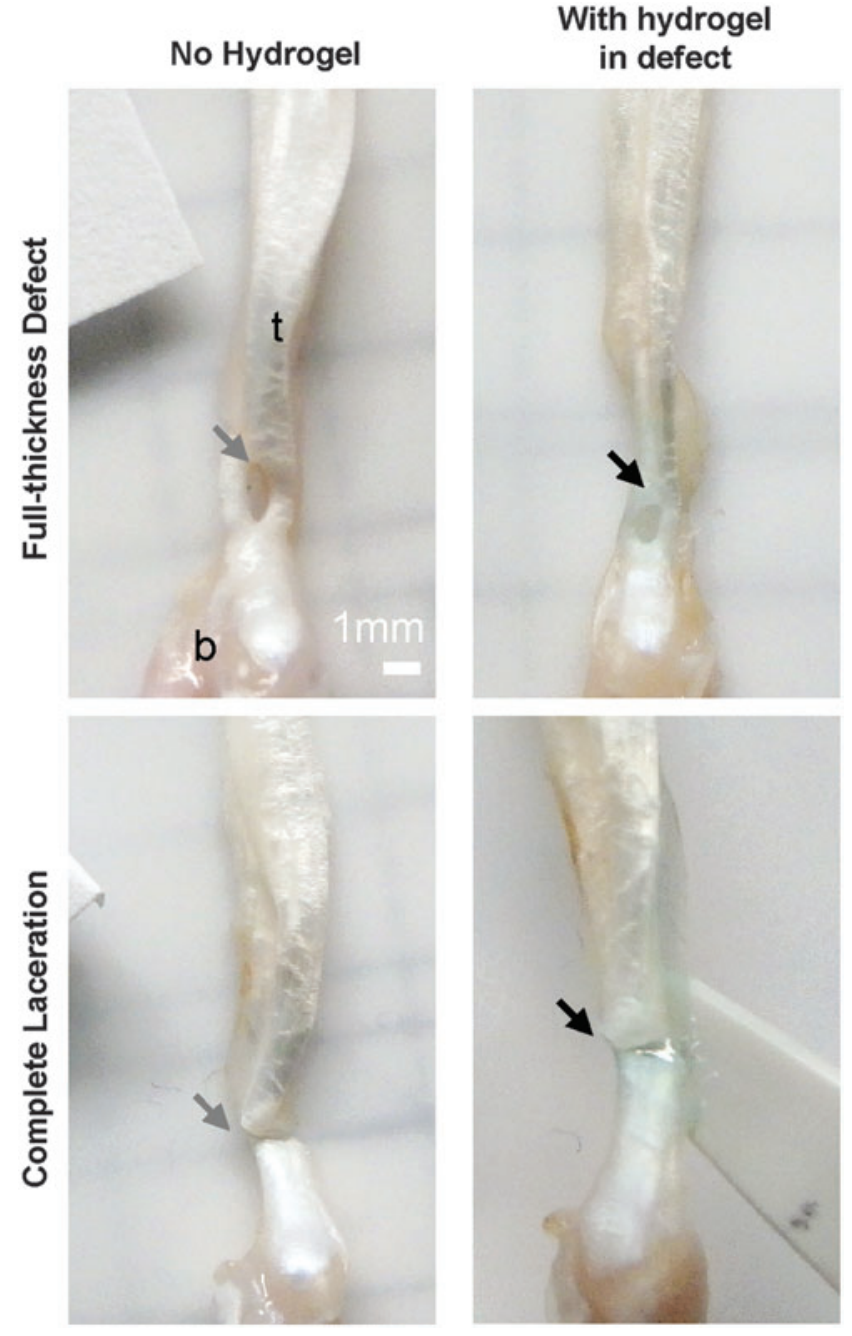

FIG. 4. Macroscopically, a physical interface between tendon defects and hydrogel formed after photopolymerization. To visualize the tendon-hydrogel interface, full-thickness and complete laceration defect models in the rat Achilles tendon were imaged before (no hydrogel, gray arrows) and after hydrogel photopolymerization within the defect sites (with hydrogel in defect, black arrows). t: tendon, b: bone (calcaneus). See the Supplementary Video for further visualization. Scale bar: $1 \mathrm{~mm}$. Color images are available online.

prevented separation between the tendon stumps following complete laceration (Supplementary Video S1). The concentration of maleimide-functionalized AF647 used within the hydrogel precursor solution was detectable with a concentration of AF647 at $80 \mu \mathrm{M}$ underneath rat skin by imaging with IVIS ${ }^{\mathrm{TM}}$, whereas $<50 \mu \mathrm{M}$ was not detectable (Fig. 5B).

Long-term retention. In Achilles full-thickness defects (Fig. 6A), hydrogels with and without mfCMP remained in place and intact for over 2 weeks with fluid agitation (Fig. 6B). For the complete laceration group, all tendonhydrogel constructs remained intact at 3 days (Fig. 6B). However, the majority of the hydrogels broke by 14 days at the tendon-hydrogel interface (Fig. 6B) and 33\% $(n=2)$ remained fully intact (not shown). Notably, for all constructs that broke, the hydrogel remained adhered to the tendon stumps (Fig. 6B).
The radiant efficiency of each hydrogel was quantified and used as a readout of fluorophore loss due to potential degradation over time from agitation. No differences in AF647 radiant efficiency were detected between either of the hydrogel or defect groups, suggesting similar fluorophore loss and degradation rates with or without mfCMP (Fig. 6C). With all hydrogels grouped together, the half-life of AF647 was nearly 5 days and the radiant efficiency remained well above the detectable limit after 2 weeks of incubation, indicating successful long-term retention and minimal degradation under agitation (Fig. 6C).

\section{Mechanical support}

Inclusion of hydrogels in a rat model of partial-thickness rotator cuff attachment injury ${ }^{47,48}$ resulted in increased ultimate load in tension $(24.3 \pm 4.1 \mathrm{~N})$ compared to empty defect controls $(21.1 \pm 3.6 \mathrm{~N})$, but did not fully recover the mechanical properties of intact attachments (Fig. 7A, B). No other mechanical properties measured were significantly different between groups (Supplementary Fig. S12). One sample was excluded and not tested due to scalpel damage during dissection.

\section{Discussion}

In this study, we first developed success criteria and then experimentally demonstrated that PEG-based hydrogels meet many of these criteria. Synthetic hydrogels offer opportunities for deliberate and tunable control over the biophysical and biochemical cues for directing cell function and fate during healing. Specifically, the material stiffness, structure, and degradability are known to direct the behavior of stem cells, macrophages, and tendon fibroblasts. ${ }^{49-53}$ In addition, stiffness and degradability do not only direct cell differentiation $^{54,55}$ but also may influence invasion. ${ }^{32}$ Biochemical cues such as receptor-binding peptides and collagen mimetic peptides have been shown to modulate cell bioactivity. ${ }^{56,57}$ For example, synthetic PEG-peptide-based ECM-mimics that contain integrin-binding collagen mimetic peptides have been shown to direct MSC differentiation toward tenogenic, chondrogenic, and osteogenic lineages, ${ }^{24,58}$ and tenogenic-differentiation of MSCs may improve in vivo tendon repair. ${ }^{59}$

Our established success criteria and a set of experimental approaches for preclinical studies rigorously assessed the efficacy of hydrogels using a combination of in vitro, ex vivo, and in vivo applications. Broadly, we envision the use of these materials as cell-free scaffolds for promoting healing and set out to test this accordingly, although the methods established here could be utilized in future applications for cell delivery. ${ }^{60,61}$

Beyond the provisional synthetic matrix of hydrogels, ECM secreted by cells, such as collagen type-I, is a tunable factor within engineered hydrogels and can influence hydrogel success. ${ }^{62-64}$ In this work, we observed collagen type-I in the pericellular matrix of hMSCs in 3D culture with or without mfCMPs, yet, increased cell elongation was only observed in the presence of assembled mfCMPs (triple helical assembly confirmation shown in Supplementary Fig. S13), consistent with previous work, in which cell morphology was quantified in response to mfCMPs. ${ }^{23}$ Such behavior represents a cellular response to mfCMPs that may 
FIG. 5. In situ imaging of hydrogels using IVIS ${ }^{\text {TM }}$. (A) AF647 was prereacted with PEG-4SH before photopolymerization to form fluorescent hydrogels.

(B) IVIS ${ }^{\mathrm{TM}}$ images of fluorescent hydrogels with titrated concentrations of AF647. Color images are available online.
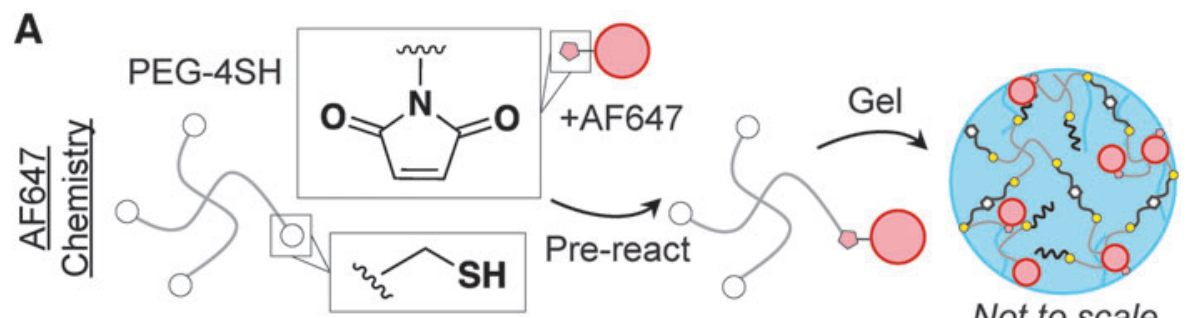

B

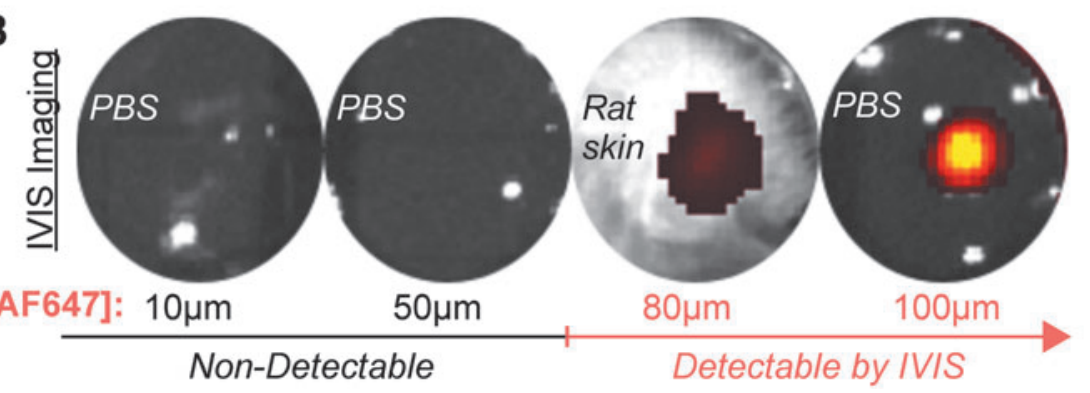

FIG. 6. Hydrogels remained adhered to tendon defects for long-term under fluid agitation. (A)

Schematic of Achilles tendon defect models and hydrogel rocking experiments. (B) Representative heat maps of AF647-hydrogel signal intensity for full-thickness defects and complete laceration tendon-hydrogel constructs with or without mfCMP after 2 h, 3 days, and 14 days of rocking in phosphate-buffered saline. (C) Quantified signal intensity (normalized radiant efficiency) of all hydrogels as individual groups (dots) and grouped together (shaded blue, standard deviation of all groups). The half-life of AF647 signal within hydrogels was $\sim 5$ days (blue line, one phase-decay fit). Samples were incubated at $37^{\circ} \mathrm{C}$ from 1- to 3-day time points to determine the effect of physiological temperature (gray bar). Black bars: significant difference between time points for grouped data $(p<0.05)$. Color images are available online.
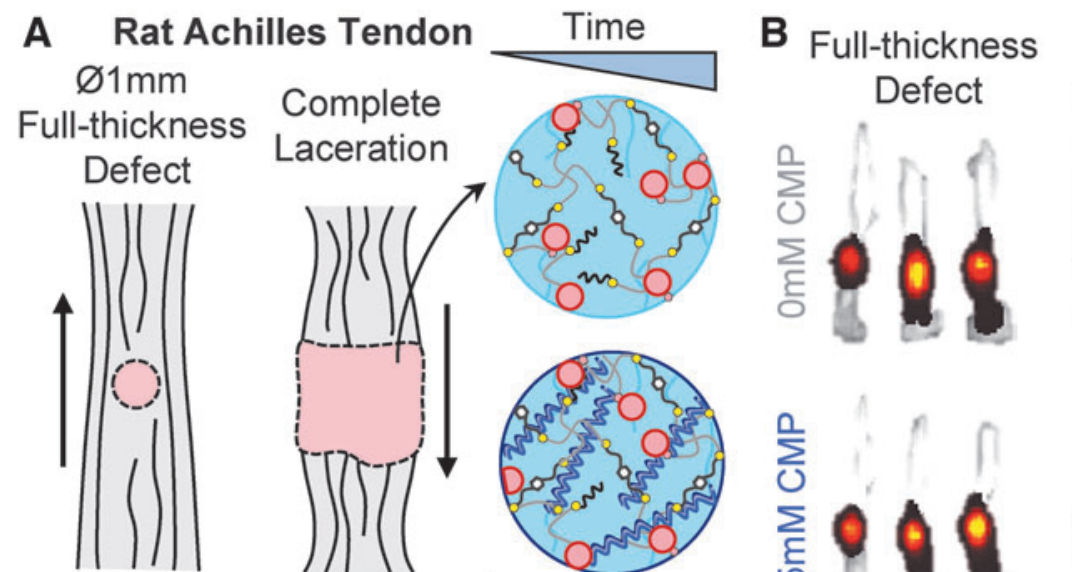

Complete Defect

Laceration

\section{Shear applied by rocking in saline for 2-weeks}

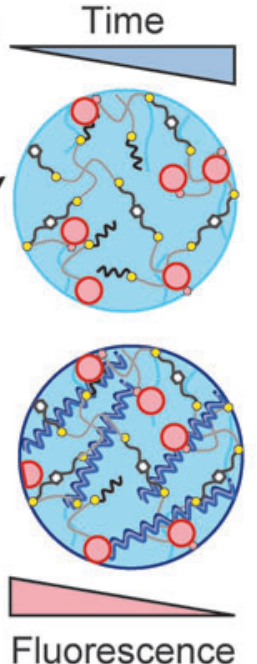

\section{Complete}

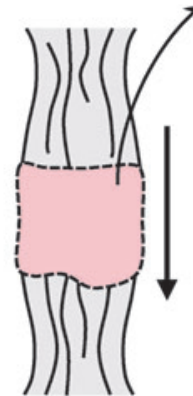

Fluorescence
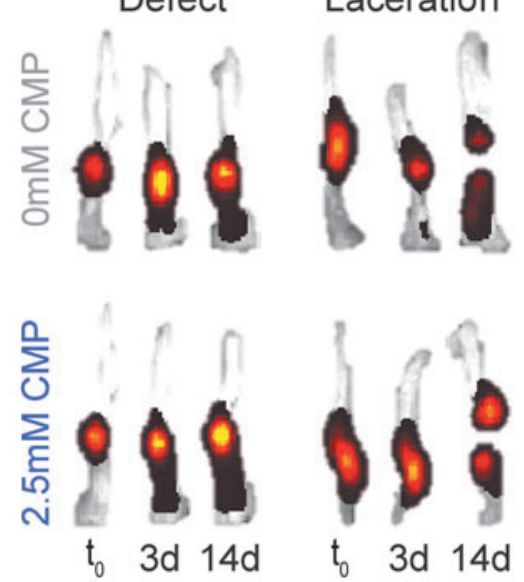

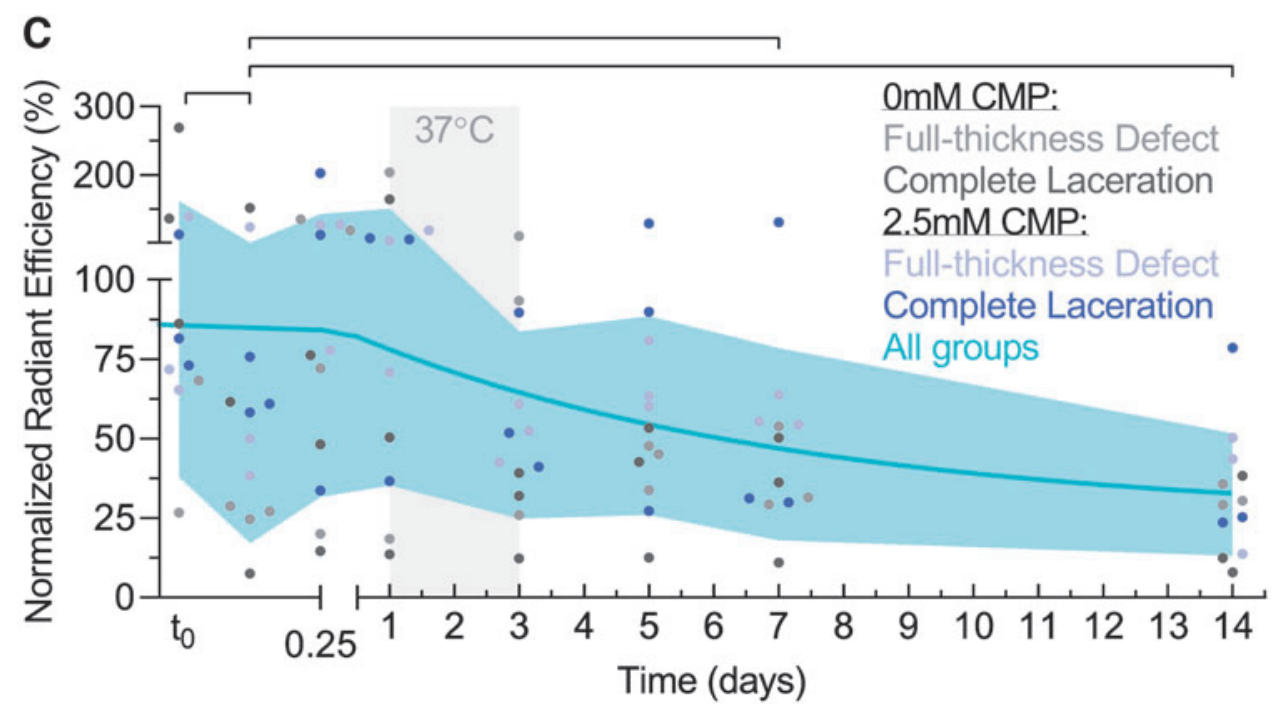



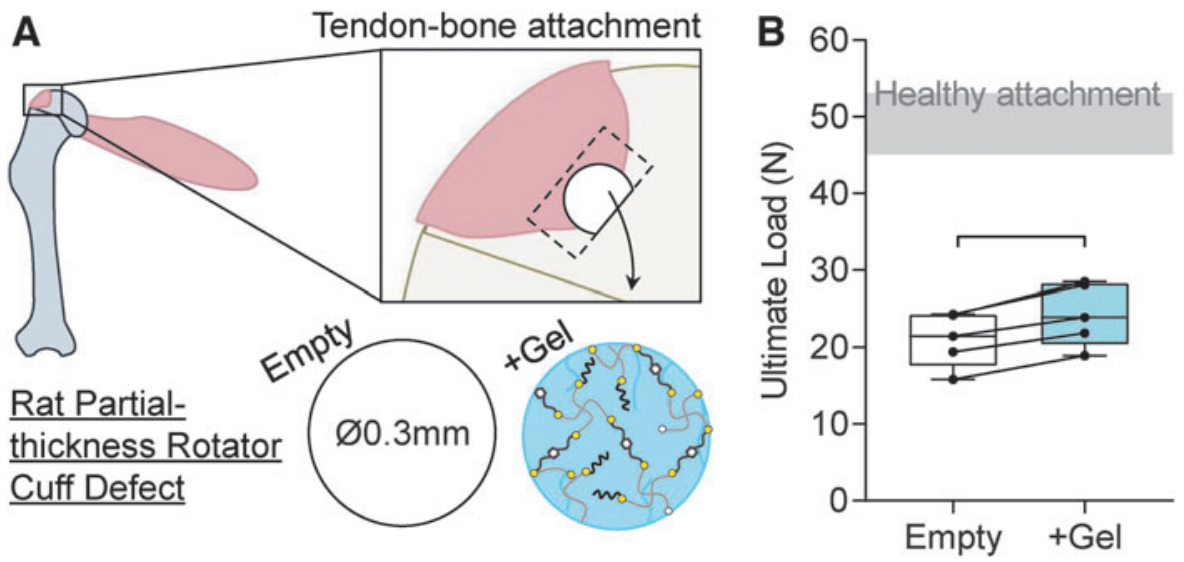

FIG. 7. Hydrogels provide mechanical support upon in situ formation in defects. (A) Schematic of the rat partial-thickness rotator cuff defect model and injection site of the hydrogel precursor solution for in situ photopolymerization within the defect. (B) Ultimate load of empty and hydrogel-filled defects with respect to noninjured tendon (intact healthy attachment, $n=2$ ) and paired-limb comparison between empty and hydrogel groups (paired symbols of individual data points). Data are presented as median $\pm 95 \%$ confidence intervals. Black bars: significant difference between groups $(p<0.05)$. Color images are available online.

be a function of both ECM composition and structure. Bioorthogonal labeling of hydrogels may be useful to determine the spatiotemporal effects of the cell-secreted ECM in hydrogels ${ }^{63}$ in vitro and in preclinical models in vivo. ${ }^{65,66}$

Collagen-based hydrogels for the delivery of biologic supplements have been shown to support healing of the torn human anterior cruciate ligament, ${ }^{67,68}$ lending substantial clinical evidence that hydrogels are retained in and suitable for healing of mechanically demanding environments. While a combination of suture repair with hydrogel delivery may be necessary to maintain mechanical support, ${ }^{67}$ we demonstrated that PEG-peptide hydrogels without suture repair can provide mechanical support to lacerated tendons at the time of gel crosslinking. Furthermore, these hydrogels, which we showed have similar mechanical properties to ECM of developing tendon, ${ }^{23,44}$ offer tunable control over biochemical cues, and enable a more targeted approach to improve healing.

In particular, the loose, fibrous structure provided by assembled mfCMPs ${ }^{23}$ is not unlike the immature fibril intermediates present in early stages of collagen fibrillogenesis during tendon development that cells (tendon fibroblasts in particular) go on to organize both linearly and laterally to form larger, aligned fibrils found in the ultrastructure of mature tendons. ${ }^{69,70}$ Indeed, in preclinical studies in the literature to date, hydrogels that incorporate mechanobiological cues of tendon development, ${ }^{24,71}$ healthy tendon ECM, ${ }^{20,72,73}$ or the ECM involved in tendon regeneration ${ }^{74}$ have shown benefits for tendon healing both in vitro and in vivo.

More broadly, the presence of fibrils has been shown to increase cell motility and provide guidance for directionality of cell motility ${ }^{33,75-77}$; as the PEG-peptide synthetic matrix contains MMP-cleavable peptide linkers that enable celldriven degradation and cell migration, ${ }^{78,79}$ opportunities for future studies include examination of the interplay between assembled mfCMP nanostructures with biochemical and mechanical properties of the synthetic matrix for examining their impact on cell motility and organization for promoting tissue regeneration. Further, future research defining the ECM present in healthy and regenerated tendons, as well as further insights into the mechanical cues present during tendon development ${ }^{44,80}$ and postnatal growth, ${ }^{81}$ may help clarify the mechanisms of action for improved healing using these hydrogels.

\section{Conclusion}

In summary, we suggest that multiple, individual experiments for each criterion with carefully selected controls be performed to test materials against these success criteria. The success criteria and validation experiments should be tailored for the needs of the material before experimental testing. Rigorous evaluation criteria of hydrogels for tendon repair are essential for reducing rates of reinjury. Incorporating the success criteria we have defined here, along with adherence to other validated standards, into basic science investigations of hydrogels for tendon repair may increase the likelihood for successful repair and reduce the time from bench-to-bedside.

\section{Disclosure Statement}

No competing financial interests exist.

\section{Funding Information}

This research was supported by Eunice Kennedy Shriver National Institute of Child Health and Human Development of the National Institutes of Health (K12HD073945), University of Delaware Research Foundation Strategic Initiatives (19A00297), and Delaware Clinical and Translational Research Accelerating Clinical and Translational Research grant funded by an Institutional Development Award from the National Institute of General Medical Sciences of the National Institutes of Health (U54GM104941). E.M.F. was supported, in part, by a fellowship from the National Science Foundation Systems Biology of Cells in Engineered Environments (SBE2) Integrative Graduate Education and Research Traineeship (IGERT) Program (1144726). Instrumentation support was provided, in part, by the Delaware Centers of Biomedical Research Excellence (COBRE) programs supported by grants from 
National Institute of General Medical Sciences of the National Institutes of Health (P20GM104316, 5 P30 GM11075802), University of Delaware Nuclear and Magnetic Resonance and Mass Spectrometry Core facilities, and the groups of Wilfred Chen and Dawn Elliott.

\section{Supplementary Material}

Supplementary Data

Supplementary Figure S1

Supplementary Figure S2

Supplementary Figure S3

Supplementary Figure S4

Supplementary Figure S5

Supplementary Figure S6

Supplementary Figure S7

Supplementary Figure S8

Supplementary Figure S9

Supplementary Figure S10

Supplementary Figure S11

Supplementary Figure S12

Supplementary Figure S13

Supplementary Table S1

Supplementary Table S2

Supplementary Table S3

Supplementary Table S4

Supplementary Video S1

\section{References}

1. United States Bone and Joint Initiative. The burden of musculoskeletal diseases in the united states (BMUS). Report no.: forth edition, forthcoming. Available from: https://boneandjointburden.org (last accessed May 1, 2020).

2. Mason, M.L., and Shearon, C.G. The process of tendon repair: an experimental study of tendon suture and tendon graft. Arch Surg 25, 615, 1932.

3. Nilsson-Helander, K., Grävare Silbernagel, K., Thomeé, R., et al. Acute Achilles tendon rupture: a randomized, controlled study comparing surgical and nonsurgical treatments using validated outcome measures. Am J Sports Med 38, 2186, 2010.

4. Olsson, N., Silbernagel, K.G., Eriksson, B.I., et al. Stable surgical repair with accelerated rehabilitation versus nonsurgical treatment for acute Achilles tendon ruptures: a randomized controlled study. Am J Sports Med 41, 2867, 2013.

5. Shibayama, K., Sugaya, H., Matsuki, K., et al. Repair integrity and functional outcomes after arthroscopic suture bridge subscapularis tendon repair. Arthroscopy 34, 2541, 2018.

6. Randelli, P.S., Menon, A., Nocerino, E., et al. Long-term results of arthroscopic rotator cuff repair: initial tear size matters: a prospective study on clinical and radiological results at a minimum follow-up of 10 years. Am J Sports Med 47, 2659, 2019.

7. Nourissat, G., Berenbaum, F., and Duprez, D. Tendon injury: from biology to tendon repair. Nat Rev Rheumatol 11, 223, 2015.

8. Howell, K., Chien, C., Bell, R., et al. Novel model of tendon regeneration reveals distinct cell mechanisms underlying regenerative and fibrotic tendon healing. Sci Rep 7, 45238, 2017.

9. Freedman, B.R., Rodriguez, A.B., Hillin, C.D., et al. Tendon healing affects the multiscale mechanical, struc- tural and compositional response of tendon to quasi-static tensile loading. J R Soc Interface 15, 20170880, 2018.

10. International Organization of Standardization. 14:00-17:00. ISO 10993-1:2018. ISO. 2018. Available from: https://iso .org/cms/render/live/en/sites/isoorg/contents/data/standard/ 06/89/68936.html (accessed May 4,2020).

11. Butler, D.L., Goldstein, S.A., and Guilak, F. Functional tissue engineering: the role of biomechanics. J Biomech Eng 122, 570, 2000.

12. Butler, D.L., Juncosa-Melvin, N., Boivin, G.P., et al. Functional tissue engineering for tendon repair: a multidisciplinary strategy using mesenchymal stem cells, bioscaffolds, and mechanical stimulation. J Orthopaed Res 26, $1,2008$.

13. Liu, C.-F., Aschbacher-Smith, L., Barthelery, N.J., Dyment, N., Butler, D., and Wylie, C. What we should know before using tissue engineering techniques to repair injured tendons: a developmental biology perspective. Tissue Eng Part B Rev 17, 165, 2011.

14. Rodrigues, M.T., Reis, R.L., and Gomes, M.E. Engineering tendon and ligament tissues: present developments towards successful clinical products. J Tissue Eng Regen Med 7, 673, 2013.

15. Breidenbach, A.P., Gilday, S.D., Lalley, A.L., et al. Functional tissue engineering of tendon: establishing biological success criteria for improving tendon repair. J Biomech 47, 1941, 2014.

16. Guilak, F., Butler, D.L., Goldstein, S.A., and Baaijens, F.P.T. Biomechanics and mechanobiology in functional tissue engineering. J Biomech 47, 1933, 2014.

17. No, Y.J., Castilho, M., Ramaswamy, Y., and Zreiqat, H. Role of biomaterials and controlled architecture on tendon/ ligament repair and regeneration. Adv Mater 32, 1904511, 2019.

18. Vedadghavami, A., Minooei, F., Mohammadi, M.H., et al. Manufacturing of hydrogel biomaterials with controlled mechanical properties for tissue engineering applications. Acta Biomater 62, 42, 2017.

19. Butler, D.L., Gooch, C., Kinneberg, K.R.C., et al. The use of mesenchymal stem cells in collagen-based scaffolds for tissue-engineered repair of tendons. Nat Protoc 5, 849, 2010.

20. Farnebo, S., Farnebo, L., Kim, M., Woon, C., Pham, H., and Chang, J. Optimized repopulation of tendon hydrogel: synergistic effects of growth factor combinations and adipose-derived stem cells. Hand (N Y) 12, 68, 2017.

21. O'Keefe, R.J., Tuan, R.S., Lane, N.E., et al. American Society for bone and mineral research-orthopaedic research society joint task force report on cell-based therapiessecondary publication. J Orthopaed Res 38, 485, 2020.

22. Miranda-Nieves, D., and Chaikof, E.L. Collagen and elastin biomaterials for the fabrication of engineered living tissues. ACS Biomater Sci Eng 3, 694, 2017.

23. Hilderbrand, A.M., Ford, E.M., Guo, C., Sloppy, J.D., and Kloxin, A.M. Hierarchically structured hydrogels utilizing multifunctional assembling peptides for 3D cell culture. Biomater Sci 8, 1256, 2020.

24. Rehmann, M.S., Luna, J.I., Maverakis, E., and Kloxin, A.M. Tuning microenvironment modulus and biochemical composition promotes human mesenchymal stem cell tenogenic differentiation. J Biomed Mater Res 104, 1162, 2016.

25. Kharkar, P.M., Rehmann, M.S., Skeens, K.M., Maverakis, E., and Kloxin, A.M. Thiol-ene click hydrogels for therapeutic delivery. ACS Biomater Sci Eng 2, 165, 2016. 
26. Stahl, P.J., Romano, N.H., Wirtz, D., and Yu, S.M. PEGbased hydrogels with collagen mimetic peptide-mediated and tunable physical cross-links. Biomacromolecules 11, 2336, 2010.

27. Cereceres, S., Touchet, T., Browning, M.B., et al. Chronic wound dressings based on collagen-mimetic proteins. Adv Wound Care 4, 444, 2015.

28. Benhardt, H., Sears, N., Touchet, T., and Cosgriff-Hernandez, E. Synthesis of collagenase-sensitive polyureas for ligament tissue engineering. Macromol Biosci 11, 1020, 2011.

29. Holloway, J.L., Lowman, A.M., VanLandingham, M.R., and Palmese, G.R. Interfacial optimization of fiberreinforced hydrogel composites for soft fibrous tissue applications. Acta Biomater 10, 3581, 2014.

30. Qiu, Y., Lei, J., Koob, T.J., and Temenoff, J.S. Cyclic tension promotes fibroblastic differentiation of human MSCs cultured on collagen-fibre scaffolds. J Tissue Eng Regen Med 10, 989, 2016.

31. Qu, F., Holloway, J.L., Esterhai, J.L., Burdick, J.A., and Mauck, R.L. Programmed biomolecule delivery to enable and direct cell migration for connective tissue repair. Nat Commun 8, 1780, 2017.

32. Song, K.H., Heo, S.-J., Peredo, A.P., Davidson, M.D., Mauck, R.L., and Burdick, J.A. Influence of fiber stiffness on meniscal cell migration into dense fibrous networks. Adv Healthc Mater 9, 1901228, 2020.

33. Wade, R.J., Bassin, E.J., Gramlich, W.M., and Burdick, J.A. Nanofibrous hydrogels with spatially patterned biochemical signals to control cell behavior. Adv Mater 27, 1356, 2015.

34. Grier, W.K., Chang, R.A.S.H., Ramsey, M.D., and Harley, B.A.C. The influence of cyclic tensile strain on multicompartment collagen-GAG scaffolds for tendon-bone junction repair. Connect Tissue Res 60, 530, 2019.

35. Vunjak-Novakovic, G., Altman, G., Horan, R., and Kaplan, D.L. Tissue engineering of ligaments. Annu Rev Biomed Eng 6, 131, 2004.

36. Pascual-Garrido, C., Aisenbrey, E.A., Rodriguez-Fontan, F., Payne, K.A., Bryant, S.J., and Goodrich, L.R. Photopolymerizable injectable cartilage mimetic hydrogel for the treatment of focal chondral lesions: a proof of concept study in a rabbit animal model. Am J Sports Med 47, 212, 2019.

37. Lin, C.-C., Ki, C.S., and Shih, H. Thiol-norbornene photoclick hydrogels for tissue engineering applications. J Appl Polym Sci 132, 41563, 2015.

38. Patterson, J., and Hubbell, J.A. Enhanced proteolytic degradation of molecularly engineered PEG hydrogels in response to MMP-1 and MMP-2. Biomaterials 31, 7836, 2010.

39. Minkwitz, S., Schmock, A., Kurtoglu, A., et al. Timedependent alterations of MMPs, TIMPs and tendon structure in human Achilles tendons after acute rupture. Int $\mathbf{J}$ Mol Sci 18, 2199, 2017.

40. Karousou, E., Ronga, M., Vigetti, D., Passi, A., and Maffulli, N. Collagens, proteoglycans, MMP-2, MMP-9 and TIMPs in human Achilles tendon rupture. Clin Orthop Relat Res 466, 1577, 2008.

41. Sawicki, L.A., and Kloxin, A.M. Design of thiol-ene photoclick hydrogels using facile techniques for cell culture applications. Biomater Sci 2, 1612, 2014.

42. Sawicki, L.A., and Kloxin, A.M. Light-mediated formation and patterning of hydrogels for cell culture applications. J Vis Exp e54462, 2016.
43. Rehmann, M.S., Skeens, K.M., Kharkar, P.M., et al. Tuning and predicting mesh size and protein release from step growth hydrogels. Biomacromolecules 18, 3131, 2017.

44. Marturano, J.E., Arena, J.D., Schiller, Z.A., Georgakoudi, I., and Kuo, C.K. Characterization of mechanical and biochemical properties of developing embryonic tendon. Proc Natl Acad Sci U S A 110, 6370, 2013.

45. Soleimani, M., and Nadri, S. A protocol for isolation and culture of mesenchymal stem cells from mouse bone marrow. Nat Protoc 4, 102, 2009.

46. Schindelin, J., Arganda-Carreras, I., Frise, E., et al. Fiji: an open-source platform for biological-image analysis. Nat Methods 9, 676, 2012.

47. Lemmon, E.A., Locke, R.C., Szostek, A.K., Ganji, E., and Killian, M.L. Partial-width injuries of the rat rotator cuff heal with fibrosis. Connect Tissue Res 59, 437, 2018.

48. Locke, R.C., Peloquin, J.M., Lemmon, E.A., Szostek, A., Elliott, D.M., and Killian, M.L. Strain distribution of intact rat rotator cuff tendon-to-bone attachments and attachments with defects. J Biomech Eng 139, 111007, 2017.

49. Bashur, C.A., Shaffer, R.D., Dahlgren, L.A., Guelcher, S.A., and Goldstein, A.S. Effect of fiber diameter and alignment of electrospun polyurethane meshes on mesenchymal progenitor cells. Tissue Eng Part A 15, 2435, 2009.

50. Popielarczyk, T.L., Nain, A.S., and Barrett, J.G. Aligned nanofiber topography directs the tenogenic differentiation of mesenchymal stem cells. Appl Sci 7, 59, 2017.

51. Schoenenberger, A.D., Tempfer, H., Lehner, C., et al. Macromechanics and polycaprolactone fiber organization drive macrophage polarization and regulate inflammatory activation of tendon in vitro and in vivo. Biomaterials 249, 120034, 2020.

52. Baker, B.M., Nathan, A.S., Gee, A.O., and Mauck, R.L. The influence of an aligned nanofibrous topography on human mesenchymal stem cell fibrochondrogenesis. Biomaterials 31, 6190, 2010.

53. Nerurkar, N.L., Sen, S., Baker, B.M., Elliott, D.M., and Mauck, R.L. Dynamic culture enhances stem cell infiltration and modulates extracellular matrix production on aligned electrospun nanofibrous scaffolds. Acta Biomater 7, 485, 2011.

54. Discher, D.E., Janmey, P., and Wang, Y. Tissue cells feel and respond to the stiffness of their substrate. Science 310, 1139, 2005.

55. Guimarães, C.F., Gasperini, L., Marques, A.P., and Reis, R.L. The stiffness of living tissues and its implications for tissue engineering. Nat Rev Mater 5, 351, 2020.

56. Stahl, P.J., and Yu, S.M. Encoding cell-instructive cues to PEG-based hydrogels via triple helical peptide assembly. Soft Mater 8, 10409, 2012.

57. Kharkar, P.M., Kiick, K.L., and Kloxin, A.M. Designing degradable hydrogels for orthogonal control of cell microenvironments. Chem Soc Rev 42, 7335, 2013.

58. Lee, H.J., Yu, C., Chansakul, T., et al. Enhanced chondrogenesis of mesenchymal stem cells in collagen mimetic peptide-mediated microenvironment. Tissue Eng Part A 14, 1843, 2008.

59. Hsieh, C.-F., Alberton, P., Loffredo-Verde, E., et al. Scaffold-free Scleraxis-programmed tendon progenitors aid in significantly enhanced repair of full-size Achilles tendon rupture. Nanomedicine 11, 1153, 2016.

60. Pittenger, M.F., Discher, D.E., Péault, B.M., Phinney, D.G., Hare, J.M., and Caplan, A.I. Mesenchymal stem cell perspective: cell biology to clinical progress. Regen Med 4, 22, 2019. 
61. Wu, R.-X., Xu, X.-Y., Wang, J., He, X.-T., Sun, H.-H., and Chen, F.-M. Biomaterials for endogenous regenerative medicine: coaxing stem cell homing and beyond. Appl Mater Today 11, 144, 2018.

62. Horton, E.R., Vallmajo-Martin, Q., Martin, I., Snedeker, J.G., Ehrbar, M., and Blache, U. Extracellular matrix production by mesenchymal stromal cells in hydrogels facilitates cell spreading and is inhibited by FGF-2. Adv Healthc Mater 9, 1901669, 2020.

63. Loebel, C., Kwon, M.Y., Wang, C., Han, L., Mauck, R.L., and Burdick, J.A. Metabolic labeling to probe the spatiotemporal accumulation of matrix at the chondrocytehydrogel interface. Adv Funct Mater 1909802, 2020.

64. Blache, U., Stevens, M.M., and Gentleman, E. Harnessing the secreted extracellular matrix to engineer tissues. Nat Biomed Eng 4, 357, 2020.

65. Calve, S., Witten, A.J., Ocken, A.R., and Kinzer-Ursem, T.L. Incorporation of non-canonical amino acids into the developing murine proteome. Sci Rep 6, 32377, 2016.

66. Nessen, M.A., Kramer, G., Back, J., et al. Selective enrichment of azide-containing peptides from complex mixtures. J Proteome Res 8, 3702, 2009.

67. Murray, M.M., Fleming, B.C., Badger, G.J., et al. bridgeenhanced anterior cruciate ligament repair is not inferior to autograft anterior cruciate ligament reconstruction at 2 years: results of a prospective randomized clinical trial. Am J Sports Med 48, 1305, 2020.

68. Murray, M.M., Kiapour, A.M., Kalish, L.A., et al. Predictors of healing ligament size and magnetic resonance signal intensity at 6 months after bridge-enhanced anterior cruciate ligament repair. Am J Sports Med 47, 1361, 2019.

69. Zhang, G., Young, B.B., Ezura, Y., et al. Development of tendon structure and function: regulation of collagen fibrillogenesis. J Musculoskelet Neuronal Interact 5, 5, 2005.

70. Connizzo, B.K., Yannascoli, S.M., and Soslowsky, L.J. Structure-function relationships of postnatal tendon development: a parallel to healing. Matrix Biol 32, 106, 2013.

71. Marturano, J.E., Schiele, N.R., Schiller, Z.A., Galassi, T.V., Stoppato, M., and Kuo, C.K. Embryonically inspired scaffolds regulate tenogenically differentiating cells. J Biomech 49, 3281, 2016.

72. Kaizawa, Y., Leyden, J., Behn, A.W., et al. Human tendonderived collagen hydrogel significantly improves biomechanical properties of the tendon-bone interface in a chronic rotator cuff injury model. J Hand Surg 44, 899.e1, 2019.

73. Kaizawa, Y., Franklin, A., Leyden, J., et al. Augmentation of chronic rotator cuff healing using adipose-derived stem cell-seeded human tendon-derived hydrogel. J Orthop Res 37, 877, 2019.

74. Paredes, J.J., Pekmezian, A., and Andarawis-Puri, N. MRL/ $\mathrm{MpJ}$ tendon matrix derived therapeutic promotes improved healing outcomes in scar-mediated canonical tendon heal- ing. J Orthopaed Res [Epub ahead of print]; DOI: 10.1002/ jor.24754, 2020.

75. Liu, S., Zhang, H., Remy, R.A., et al. Meter-long multiblock copolymer microfibers via interfacial bioorthogonal polymerization. Adv Mater 27, 2783, 2015.

76. Baker, B.M., Trappmann, B., Wang, W.Y., et al. Cellmediated fiber recruitment drives extracellular matrix mechanosensing in engineered fibrillar microenvironments. Nat Mater 14, 1262, 2015.

77. Matera, D.L., Wang, W.Y., Smith, M.R., Shikanov, A., and Baker, B.M., Fiber density modulates cell spreading in 3D interstitial matrix Mimetics. ACS Biomater Sci Eng 5, 2965, 2019.

78. Singh, S.P., Schwartz, M.P., Lee, J.Y., Fairbanks, B.D., and Anseth, K.S. A peptide functionalized poly(ethylene glycol) (PEG) hydrogel for investigating the influence of biochemical and biophysical matrix properties on tumor cell migration. Biomater Sci 2, 1024, 2014.

79. Kyburz, K.A. and Anseth, K.S. Three-dimensional hMSC motility within peptide-functionalized PEG-based hydrogel of varying adhesivity and crosslinking density. Acta Biomater 9, 6381, 2013.

80. McBride, D.J., Trelstad, R.L., and Silver, F.H. Structural and mechanical assessment of developing chick tendon. Int J Biol Macromol 10, 194, 1988.

81. Ansorge, H.L., Adams, S., Birk, D.E., and Soslowsky, L.J. Mechanical, compositional, and structural properties of the post-natal mouse Achilles tendon. Ann Biomed Eng 39, 1904, 2011.

Address correspondence to: Megan L. Killian, PhD Department of Orthopaedic Surgery University of Michigan Medical School 2021 BSRB, 109 Zina Pitcher Place Ann Arbor, MI 48019-0624 USA

E-mail:mlkillia@umich.edu

April M. Kloxin

Departments of Chemical and Biomolecular Engineering and Materials Science and Engineering University of Delaware

207 Colburn Laboratory Newark, DE 19716 USA

E-mail: akloxin@udel.edu

Received: July 17, 2020 Accepted: September 20, 2020 Online Publication Date: October 21, 2020 